05.1

\title{
Влияние термообработки на упругие и микропластические свойства ультрамелкозернистого титана с разным содержанием примесей
}

\author{
() Б.К. Кардашев ${ }^{1}$, М.В. Нарыкова ${ }^{1, \uparrow, ~ В . И . ~ Б е т е х т и н ~}{ }^{1}$, А.Г. Кадомцев ${ }^{1}$, А.Ю. Токмачева-Колобова ${ }^{2,3}$ \\ ${ }^{1}$ Физико-технический институт им. А.Ф. Иофффе РАН, Санкт-Петербург, Россия \\ ${ }^{2}$ Национальный исследовательский технологический университет „МИСиС“, Москва, Россия \\ ${ }^{3}$ Институт проблем химической фризики РАН, Черноголовка, Московская обл., Россия \\ ฯ E-mail: Maria.Narykova@mail.ioffe.ru
}

Поступило в Редакцию 9 июля 2019г.

В окончательной редакции 7 августа 2019г.

Принято к публикации 7 августа 2019г.

Обсуждаются результаты изучения влияния повышенных температур на упругие и микропластические свойства ультрамелкозернистого титана, полученного в результате интенсивной пластической деформации. Исследованы образцы трех различных партий $\alpha$-титана: ВТ1-0, Grade 4 и ПТ3-В, отличающихся друг от друга исходной поликристаллической структурой и примесным составом. Как показали эксперименты, значительные изменения структуры (размеров зерен), упругих свойств и микропластических характеристик наблюдаются только для наиболее чистого титана марки ВТ1-0. Термическая стабильность свойств образцов Grade 4 и ПТ3-В оказалась значительно выше, что связано с наличием в этих материалах большего количества примеси других элементов.

Ключевые слова: ультрамелкозернистый титан, модуль Юнга, внутреннее трение, упругие свойства.

DOI: 10.21883/PJTF.2019.22.48650.17969

Настоящая работа посвящена исследованию влияния интенсивной пластической деформации (ИПД) на упругопластические свойства титана. Этот металл в ультрамелкозернистом (УМЗ) состоянии после ИПД используется в медицине в качестве имплантата [1-4], поскольку мелкое зерно обеспечивает его высокую прочность [5]. Большое значение здесь имеет постоянство упругих и других механических свойств, в частности их термическая стабильность. Работа посвящена изучению влияния повышенных температур на поликристаллическую структуру, упругие и микропластические свойства титана различных марок, используемых в медицинской практике.

В наших экспериментах использовались три марки $\alpha$-титана: BT1-0, Grade 4 и ПТ3-B, существенно отличающиеся друг от друга содержанием примесей. В титане ВТ1-0 суммарная концентрация примесей была около 0.28 wt.\%, из которых 0.12 wt.\% составляло железо. Другая марка (Grade 4) содержала 0.78 wt.\% примесей, в том числе 0.39 wt.\% железа. Больше всего примеси (> 5.8 wt.\%) было в титане ПТ3-В, из которых 3.5 wt.\% составлял алюминий, 2 wt.\% - ванадий, 0.15 wt.\% железо.

Перевод в УМЗ-состояние осуществлялся с помощью отработанного режима винтовой и продольной прокатки [1,3]. Следует отметить, что после ИПД все исследованные марки титана имели почти одинаковую поликристаллическую структуру с размером зерен $\sim 250 \times 290 \mathrm{~nm}$. Однако исходная (до ИПД) крупнозернистая структура у них была различной. В случае ВТ1-0 зерна имели форму ламелей размером $\sim 150 \times 10 \mu \mathrm{m}$. Титан другой марки (Grade 4) имел в исходном состо- янии почти равноосную структуру со средним размером зерна около $40 \mu \mathrm{m}$. У титана ПТЗ-В в исходном состоянии наблюдались пластинчатые зерна размером $\sim 100 \times 5 \mu \mathrm{m}$.

Модуль Юнга $E$ и внутреннее трение (логарифмический декремент $\delta$ ) титана измерялись в широком диапазоне амплитуд колебательной деформации $\varepsilon$ акустическим методом составного вибратора. Этот метод представляется более надежным и информативным, чем оценка упругих свойств по данным механических испытаний, например наноиндентирования, которое практически нечувствительно [6] к влиянию пористости, или ультразвукового метода [7]. Как и в предыдущих экспериментах $[1,2]$, использовались умеренные амплитуды, такие, чтобы дислокационная структура не менялась после приложения к образцу акустической нагрузки. УМЗ-образцы титана для акустических измерений имели форму стержней прямоугольного сечения $\sim 2 \times 4 \mathrm{~mm}$ длиной около $22 \mathrm{~mm}$. Такая длина обеспечивала резонанс продольных колебаний на частотах около $100 \mathrm{kHz}$. Погрешность в определении величин модуля Юнга не превышала 1\%. Для декремента эта величина была не более $5 \%$

На основе измерений амплитудных зависимостей $E(\varepsilon)$ строились диаграммы микропластического деформирования $\sigma\left(\varepsilon_{d}\right)$, где $\sigma=E \cdot \varepsilon$ (закон Гука), а $\varepsilon_{d}-$ нелинейная неупругая микропластическая деформация. Подробности о процедуре подобных построений можно найти в [2].

Термическая обработка (отжиг) образцов проводилась в четыре этапа: 1) нагрев до $350^{\circ} \mathrm{C}$ и выдержка в течение $4 \mathrm{~h} ; 2$ ) нагрев до $430^{\circ} \mathrm{C}$ и выдержка $2 \mathrm{~h}$; 
3) нагрев до $430^{\circ} \mathrm{C}$ и выдержка $6 \mathrm{~h}$; 4) нагрев до $490^{\circ} \mathrm{C}$ и выдержка $30 \mathrm{~min}$. В результате было обнаружено, что увеличение температуры отжига и времени выдержки при фиксированной температуре приводит к плавному росту размеров зерен. Для ВТ1-0 зерно увеличивалось значительно: от начальных $250 \mathrm{~nm}$ до $1250 \mathrm{~nm}$ после выдержки при $490^{\circ} \mathrm{C}$. Для Grade 4 и ПТЗ-В зерна выросли всего лишь до 380 и $360 \mathrm{~nm}$ соответственно.

Для образцов всех партий титана после ИПД и каждого этапа термической обработки проводилось прецизионное измерение плотности (погрешность около $0.01 \%)$. Было обнаружено, что нагрев и выдержка при повышенных температурах приводят лишь к небольшому повышению плотности. Максимальный нагрев до $490^{\circ} \mathrm{C}$ увеличил плотность ВТ1-0 и Grade 4 на величину менее $0.1 \%$, а плотность ПТЗ-В - на $0.14 \%$.

На рис. 1 в качестве примера приведены амплитудные зависимости $E(\varepsilon)$ для всех образцов исследованных материалов в УМЗ-состоянии до и после термической обработки при $430^{\circ} \mathrm{C}$ в течение $2 \mathrm{~h}$. Обращает на себя внимание качественное изменение зависимости $E(\varepsilon)$ для титана BT1-0, которая стала похожей на аналогичные зависимости для других марок титана. На рис. 2 представлен пример (Grade 4) поведения диаграмм микро-

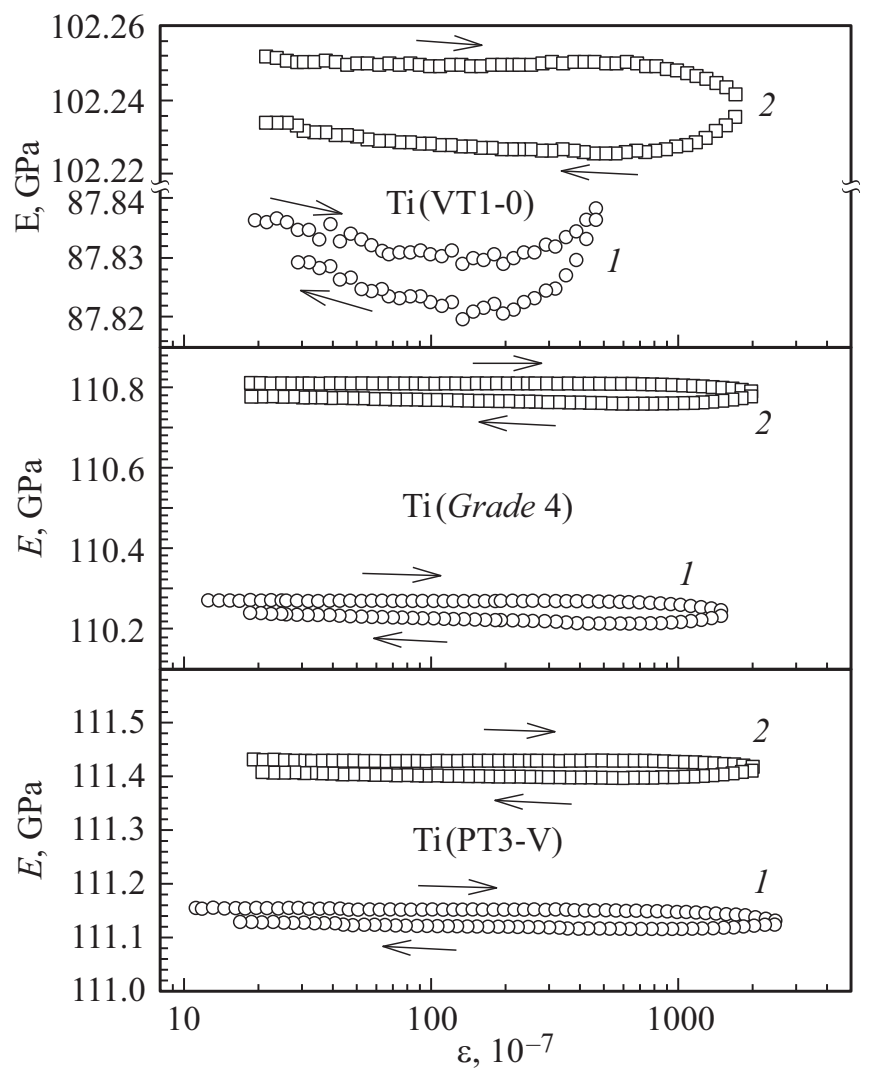

Рис. 1. Амплитудные зависимости модуля Юнга $E$ для марок титана ВТ1-0, Grade 4 и ПТ3-В до (1) и после (2) отжига при температуре $430^{\circ} \mathrm{C}$. Измерения выполнены при комнатной температуре. Стрелки указывают направление изменения амплитуды.

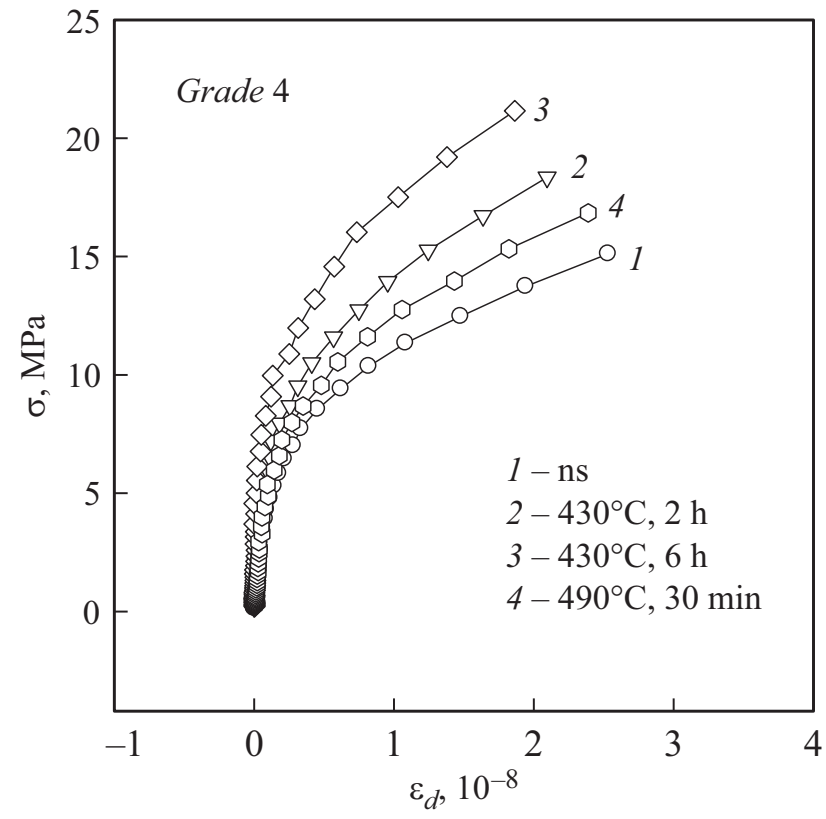

Рис. 2. Диаграммы микропластического деформирования образца наноструктурированного (ns) титана Grade 4 до (1) и после (2-4) различных термообработок.

пластического деформирования $\sigma\left(\varepsilon_{d}\right)$ в зависимости от той или иной термообработки. Из рисунков видно, что температурная обработка УМЗ-титана заметно влияет на изучаемые параметры. Однако это влияние оказывается различным для разных марок титана.

Сведения о значениях декремента $\delta_{i}$ (амплитуднонезависимые величины, измеренные при малых амплитудах), а также условного предела микротекучести $\sigma_{s}$, соответствующего некоторой фиксированной величине неупругой деформации $\left(\varepsilon_{d}=1.0 \cdot 10^{-8}\right)$, приведены в таблице.

Наиболее интересный результат выполненных исследований - существенный рост модуля Юнга с увеличением температуры и времени выдержки при повышенной температуре для титана ВТ1-0 $(\sim 20 \%)$ и очень небольшие изменения модуля для Grade 4 и ПТ3-B. Рис. 3 наглядно демонстрирует влияние температуры на поведение модуля Юнга у исследованных материалов (при построении кривых на рис. 3 не учитывалось время выдержки образцов при той или иной температуре).

Значительному росту $E$ у ВТ1-0 при нагреве до $350^{\circ} \mathrm{C}$, что хорошо видно из рис. 3 , соответствует (см. таблицу) значительное уменьшение декремента $\delta_{i}$ (более чем в 4 раза). Дальнейший нагрев до 430 и $490^{\circ} \mathrm{C}$ мало меняет $\delta_{i}$. Наблюдаются лишь небольшие изменения как в сторону увеличения, так и в сторону уменьшения. Аналогично мало меняется декремент у Grade 4 и ПТ3-В.

Что касается условного предела микротекучести $\sigma_{s}$ (см. таблицу), то здесь также наблюдаются небольшие, как правило немонотонные, изменения значений $\sigma_{s}$ при увеличении температуры и времени отжига. 
Амплитудно-независимый декремент $\delta_{i}$ и условный предел микротекучести $\sigma_{s}$ при неупругой деформации $\varepsilon_{d}=1.0 \cdot 10^{-8}$ до (ns) и после термообработки образцов нанокристаллического титана

\begin{tabular}{l|c|c|c|c|c|c}
\hline \multirow{2}{*}{ Термообработка } & \multicolumn{2}{|c|}{$\mathrm{BT} 1-0$} & \multicolumn{2}{|c}{ Grade 4 } & \multicolumn{2}{c}{ ПT3-B } \\
\cline { 2 - 7 } & $\delta_{i}, 10^{-5}$ & $\sigma_{s}, \mathrm{MPa}$ & $\delta_{i}, 10^{-5}$ & $\sigma_{s}, \mathrm{MPa}$ & $\delta_{i}, 10^{-5}$ & $\sigma_{s}, \mathrm{MPa}$ \\
\hline $20^{\circ} \mathrm{C}, \mathrm{ns}$ & 408 & - & 107 & 10.5 & 57 & 13 \\
$350^{\circ} \mathrm{C}, 4 \mathrm{~h}$ & 90.2 & 16 & 121 & 11.5 & 66 & 15 \\
$430^{\circ} \mathrm{C}, 2 \mathrm{~h}$ & 90.3 & 14 & 85 & 14 & 82 & 16 \\
$430^{\circ} \mathrm{C}, 6 \mathrm{~h}$ & 74.5 & 18.5 & 71 & 17 & 100 & 16 \\
$490^{\circ} \mathrm{C}, 30 \mathrm{~min}$ & 81.1 & 17 & 87 & 11.5 & 85 & 18
\end{tabular}

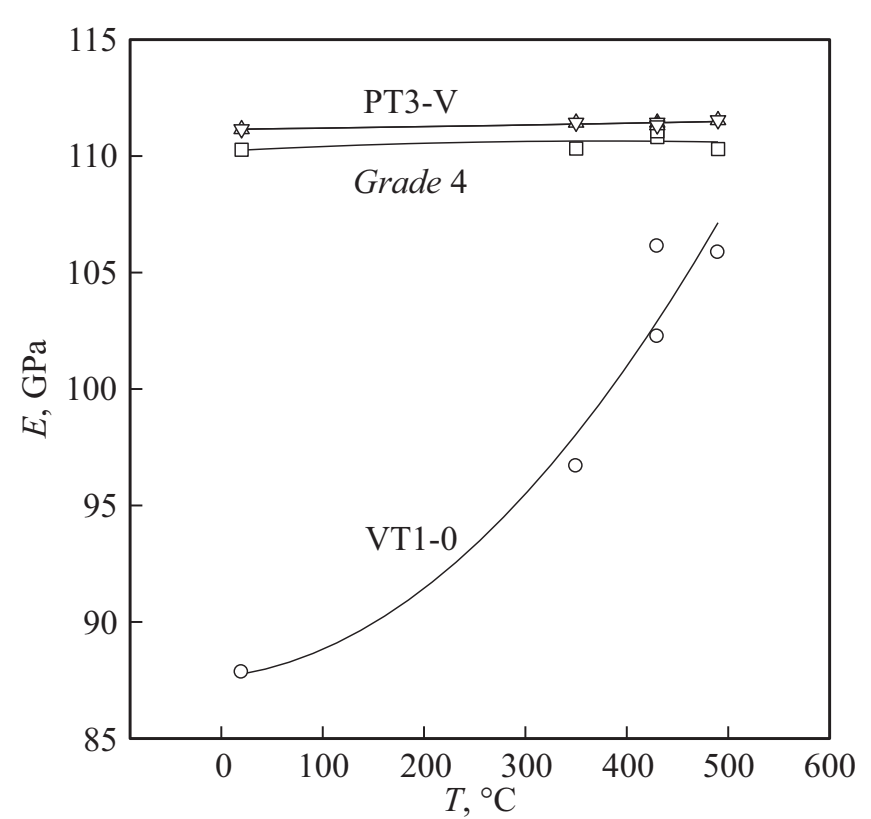

Рис. 3. Модуль Юнга образцов титана в зависимости от температуры термообработки.

Объяснить наблюдаемые явления можно следующим образом. Очевидно, что основным фактором, влияющим на термическую стабильность исследованных свойств титана, является концентрация примеси. Только малым содержанием примеси можно объяснить существенный рост размеров зерен в титане ВТ1-0 и коренное изменение зависимостей $E(\varepsilon)$ после термообработки (рис. 1). По всей видимости, этому способствует высокая подвижность дислокаций в более чистом титане по сравнению с таковой для Grade 4 и ПТ3-В, где большая концентрация примеси стабилизирует структуру.

Действительно, теория дислокационного внутреннего трения [8] объясняет увеличение модуля упругости и уменьшение декремента при отжиге диффузией точечных дефектов к дислокациям. Дефекты закрепляют дислокации, их подвижность становится меньше, дислокационная деформация затрудняется. Это сказывается на измеряемых величинах $E$ и $\delta_{i}$ : модуль Юнга растет, декремент уменьшается. Особенно ярко это видно для более чистого титана, где примеси мало и материал после ИПД находится в более неравновесном состоянии, чем в случае Grade 4 и ПТ3-В, где большое количество примеси мешает дислокациям перемещаться.

Необходимо отметить, что после нагрева до $350^{\circ} \mathrm{C}$ титан ВТ1-0 ведет себя качественно так же, как и Grade 4 и ПТ3-В. Здесь характерными являются небольшие, почти всегда немонотонные изменения всех трех параметров $\left(E, \delta_{i}\right.$ и $\left.\sigma_{s}\right)$ при увеличении температуры и длительности отжига. Это может быть связано с тем, что помимо подвижности дислокаций на эти параметры могут оказывать влияние другие факторы, такие как площадь границ зерен, пористость, суммарная плотность дислокаций и дальнодействующие поля внутренних напряжений [1]. Перечисленные факторы способны как увеличивать, так и уменьшать значения $E, \delta_{i}$ и $\sigma_{s}$. Так, увеличение размера зерна при отжиге уменьшает общую площадь границ, что приводит к уменьшению зернограничного затухания: падает $\delta_{i}$. Уменьшающаяся пористость (как отмечалось выше, плотность титана всех марок в результате отжига немного увеличивается) должна вызывать небольшой рост модуля $E$. Плотность внутризеренных дислокаций после отжига, как правило, становится меньше, что увеличивает $E$ и $\sigma_{s}$. Релаксация внутренних напряжений, имеющая место после высокотемпературного нагрева, должна, наоборот, уменьшать модуль $E$.

Таким образом, исследование влияния термообработки образцов различных марок УМЗ-титана, полученных в результате ИПД, показало, что основным фактором, который обеспечивает термическую стабильность структуры и упругопластических свойств, является концентрация примеси, которая контролирует подвижность внутризеренных дислокаций. Это обстоятельство важно учитывать при разработке использования ультрамелкозернистого титана в качестве имплантатов.

\section{Финансирование работы}

Исследование выполнено за счет гранта Российского научного фонда (проект № 19-12-00221).

\section{Конфликт интересов}

Авторы заявляют, что у них нет конфликта интересов. 


\section{Список литературы}

[1] Кардашев Б.К., Бетехтин В.И., Кадомиев А.Г., Нарыкова М.В., Колобов Ю.Р. // ЖТФ. 2017. Т. 87. В. 9. С. 1362 1366.

[2] Кардашев Б.К., Бетехтин В.И., Нарыкова М.В. // ЖТФ. 2015. T. 85. B. 12. C. $94-106$.

[3] Колобов Ю.Р. // Рос. нанотехнологии. 2009. Т. 4. № 11-12. C. 69-81.

[4] Stráskýa J., Harcubaa P., Václavováa K., Horváth K., Landa M., Srba O., Janeček M. // J. Mechan. Behav. Biomed. Mater. 2017. V. 71. P. 329-336.

[5] Valiev R.Z., Estrin Y., Horita Z., Langdon T.G., Zehetbauer M.J., Zhu Y.T. // Mater. Res. Lett. 2016. V. 4. P. 1-21.

[6] Zhou Y., Erb U., Aust K.T., Palumbo G. // Scripta Mater. 2003. V. 48. P. $825-830$.

[7] Chaim R., Heletz M. // J. Mater. Sci. 2004. V. 39. P. 3054-3061.

[8] Gremaud G. // Mater. Sci. Forum. 2001. V. 366-368. P. 178 246. 